\title{
Building a Functional Cardiograph Over Four Semesters, Part 3: Estimating Heart Rate and Respiration Rate in the Time and Frequency Domains Using MATLAB
}

\section{Dr. Gail Baura, Loyola University Chicago}

Dr. Gail Baura is a Professor and Director of Engineering at Loyola University Chicago. While creating the curriculum for this new program, she embedded multi-semester projects to increase student engagement and performance. Previously, she was a Professor of Medical Devices at Keck Graduate Institute of Applied Life Sciences, which is one of the Claremont Colleges. She received her BS Electrical Engineering degree from Loyola Marymount University, her MS Electrical Engineering and MS Biomedical Engineering degrees from Drexel University, and her PhD Bioengineering degree from the University of Washington. Between her graduate degrees, she worked as a loop transmission systems engineer at AT\&T Bell Laboratories. She then spent 13 years in the medical device industry conducting medical device research and managing research and product development at several companies. In her last industry position, Dr. Baura was Vice President, Research and Chief Scientist at CardioDynamics. She is a Fellow of the American Institute of Medical and Biological Engineering (AIMBE).

\section{Ms. Francisca Fils-Aime, Loyola University Chicago}

Francisca Fils-Aime is currently a doctoral student at Loyola University Chicago in the Research Methodology program.

\section{Vincent Chen, Loyola University Chicago}

Dr. Vincent Chen is an Assistant Professor of Biomedical Engineering with expertise in neuromodulation and rehabilitation engineering. His current research focuses on quantifying the extent of neuroplasticity induced by the application of brain and peripheral nerve stimulation.

\section{Leanne Kallemeyn, Loyola University Chicago}

Leanne Kallemeyn, Ph.D., is an Associate Professor in Research Methodologies at Loyola University Chicago. She teaches graduate-level courses in program evaluation, qualitative research methods, and mixed methods. She has been the PI on seven major evaluation projects that ranged from one to five years in length. Her scholarship focuses on practitioners' data use and evaluation capacity building within non-profits through coaching. She received a Bachelors in Psychology from Calvin College, and a PhD in Educational Psychology from the University of Illinois, Urbana-Champaign. 


\title{
Building a Functional Cardiograph Over Four Semesters: Part 3 - Estimating Heart Rate and Respiration Rate in the Time and Frequency Domains Using MATLAB
}

\begin{abstract}
At Loyola University Chicago (LUC), all engineering courses are taught using a mandatory minimal lecture style, where the majority of course meeting time is devoted to group activities. Each activity may take place during that course meeting only, over the entire semester, or over multiple semesters. Curricular contextual threads take place over multiple semesters. One such contextual thread is the cardiograph project, whereby students build a functional cardiograph that estimates heart rate (HR) and respiration rate (RR) over four semesters (first, third, fifth, and sixth semesters). In Part III, students acquire their own electrocardiogram (ECG) using a custom motherboard, with which they had programmed a Texas microcontroller to acquire and display an ECG in Part II of the project. They then estimate personal HR and RR from their ECGs in both the time and frequency domains using MATLAB.
\end{abstract}

In Part III of this study, we tested if student engagement in engineering design increased student proficiency with MATLAB. We assessed student engagement using the validated Student Response to Instructional Practices (StRIP) instrument. As these students completed the Assessing Women and Men in Engineering (AWE) annual survey during their first, third, and fifth semesters, we also considered how across participation in the cardiograph project through consecutive years may be one curricular element that contributes to students' persistence in engineering, development of engineering identity, and sense of belonging.

\section{Introduction}

The BS Engineering program at Loyola University Chicago launched in 2015, with every engineering course taught with active learning, using a version of the U.S. Air Force Academy's minimal lecture style [1-3]. Within every 50 minute course period, the first ten to fifteen minutes are devoted to reviewing fine points of the homework as a minimal lecture. The remaining course period time is devoted to collaborative and problem-based learning (PBL) [4], as active learning has been shown to increase student performance [5-8] and enhance student motivation [9].

\section{Background}

PBL is "an instructional method where relevant problems are introduced at the beginning of the instruction cycle and used to provide the context and motivation for the leaning that follows" [10]. PBL leads to improved performance and long-term knowledge retention [1114]. Compared to other active learning pedagogies, it results in increased gains in selfregulated learning [15]. The curriculum includes curricular contextual threads, which are multi-semester projects threaded through the curriculum. One of these contextual threads is the patient monitoring thread, during which each student builds her own functional cardiograph.

"Building this cardiograph is an implementation of situated learning [16], which Lave and 
Wenger first defined as 'an extended period of legitimate peripherality [that] provides learners with opportunities to make the culture of practice theirs [17].' As described by Johri, et al., this "learning takes place not through transmission of abstract knowledge, but through engagement in the 'knowledgeable skills' that are realized in the everyday activities of a community [18].” Here, students emulate the practices (to some extent) of electrical engineers in the medical device industry, which could cause them to identify with engineers practicing in industry. Solving a real-world engineering problem over several semesters may increase a student's selfidentification as an engineer [18]” [19].

At LUC, engineering students do not take a specific MATLAB programming course, as the computer science department's first programming course is based on Java. However, engineering students are introduced to MATLAB during the fourth semester in their circuits and linear systems courses. By the fifth semester, engineering juniors are expected to solve in-class and homework problems using MATLAB in three engineering courses and one engineering lab course. It is assumed that juniors are proficient in time and frequency array construction, $\mathrm{x}-\mathrm{y}$ plotting with labeling, while loops, and array indexing.

\section{Project Summary and Part I/II Results}

"For the patient monitoring contextual thread, each student builds a functional cardiograph over four semesters. The projects parts are embedded in ENGR 101 Introduction to Engineering Design (4 cr hr), ENGR 201 Experimental Engineering (3 cr hr), ENGR 324L Engineering Core Lab (1 cr hr), and ENGR 3x1L Specialty Lab (1 cr hr) (Figure 1).

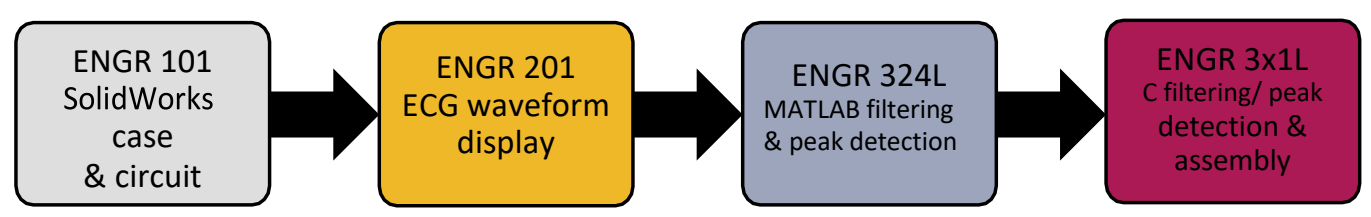

Figure 1. LUC’s Patient Monitoring Curricular Contextual Thread

In ENGR 101, students learn SolidWorks, and conduct open-ended design projects in groups. In ENGR 201, students are exposed to all three specializations (biomedical, computer, or environmental engineering) through experiments. For computer engineering exposure, students learn microcontroller basics and then conduct Part II of the project. In ENGR 324L, students conduct experiments related to core engineering courses given during the same semester, as well as Part III of the project. Each specialization has its own lab course: ENGR 341L Biomedical Engineering Lab, ENGR 351 Computer Engineering Lab, ENGR 361 Environmental Engineering Lab. One experimental time slot has been reserved in each specialty lab to conduct Part IV of the project.

As shown in Figure 1, Part I, students create a customized cardiograph case and breadboard a biopotential amplifier [20, 21] during ENGR 101 (semester 1). The biopotential amplifier/myDAQ card/LabVIEW executable that enables student ECG waveforms to be displayed is then converted to a custom motherboard that interfaces to a TI microcontroller and display, all of which sit in the case. In Part II in ENGR 201 (semester 3), students program the microcontroller to display ECG waveforms. In Part III in ENGR 324L (semester 5), students 
design and code MATLAB digital filters that separate the ECG and respiratory waveforms, and count peaks to estimate heart rate (HR) and respiration rate (RR)" [4]. "In Part IV in ENGR 3x1L (semester 6), students implement these filters and calculations in the TI microcontroller” [19], and assemble the cardiograph.

"In Part I of this study, students strongly agreed that they were engaged in active learning in the course, and this remained constant on the pre- and post-assessment. Students also reported being slightly satisfied to satisfied with their choice of engineering major" [4]. In Part II, " $100 \%$ of student groups were able to reach exemplary and satisfactory levels for LED programming, ECG signal acquisition, and graphics tasks. Post-assessment results also affirmed high levels of engagement and learning for students with the project, even in comparison with students' general experiences with the problem-based learning approach across the curriculum” [19].

\section{Part III: MATLAB Filtering and Peak Detection}

At the beginning of the ENGR 324L cardiograph lab, the first author taught the class how to recognize the $\mathrm{P}, \mathrm{Q}, \mathrm{R}, \mathrm{S}$, and $\mathrm{T}$ waves of the ECG; and how to isolate different frequency ranges with lowpass, bandpass, and highpass frequency-selective filters. She or the third author then recorded the ECG, at a sampling frequency of $1000 \mathrm{~Hz}$, of one junior within each group of two juniors. A cardiograph custom motherboard from Part II (Figure 2) was used for the recording. The acquired text file was then input into MATLAB.

Through a series of lab instructions, students were asked to estimate and then code the following using MATLAB:

1. Calculate the heart rate from four ECG beats plotted in the time domain.

2. Identify the heart rate and respiration rate from the power spectral density of the ECG, in the frequency domain.

3. Lowpass-filter the ECG waveform to isolate the respiration waveform, and calculate the respiration rate in the time domain.

4. Create a while loop that inputs 1000 ECG samples at a time and identifies each ECG peak, or R wave (Figure 3).

\section{Methodology}

\section{Participants}

A total of 32 students enrolled in ENGR 324L during semester 5 participated in the preassessment. Nineteen were part of cohort 2021 and 13 were part of cohort 2022. Thirty-four students completed the post-assessment, 23 from cohort 2021 and 11 from cohort 2022. Students do not declare their specialization of biomedical, computer, or environmental engineering and begin to take specialization courses until semester 6.

\section{Methods}

This study was part of an ongoing, longitudinal study tracking student persistence and factors that facilitated persistence. The methods for this study were similar to those reported for Part II of the cardiograph project [19], including a pre-test post-test design. 

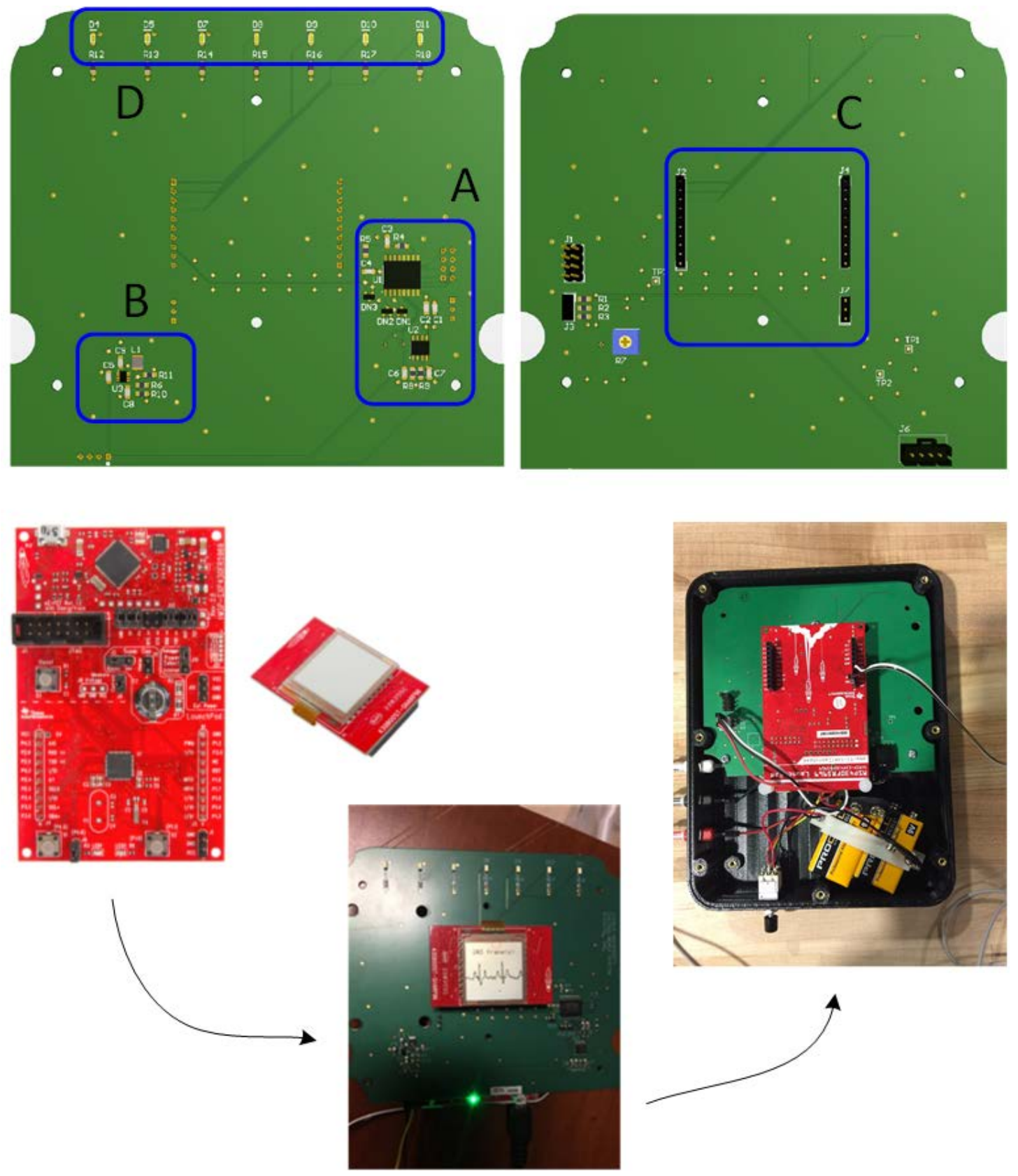

Figure 2.Cardiograph hardware: custom LUC motherboard (A: biopotential amplifier, B: analog filters, C: microcontroller interface circuitry, D: seven LEDs), TI LaunchPad development kit, Sharp LCD BoosterPack. The hardware is stacked in the personalized cardiograph top case.

\section{Tools}

An annual persistence survey [22] administered at the beginning of the fall semester of junior year included a 15 instruction items on the Student Response to Instructional Practices (StRIP) Instrument [23]. StRIP uses the constructs of value, positivity, participation, and distraction to measure the extent to which students are cognitively, affectively, and behaviorally invested in a class. StRIP pre-assessment data was available for cohort 2021, but not for cohort 2022. 

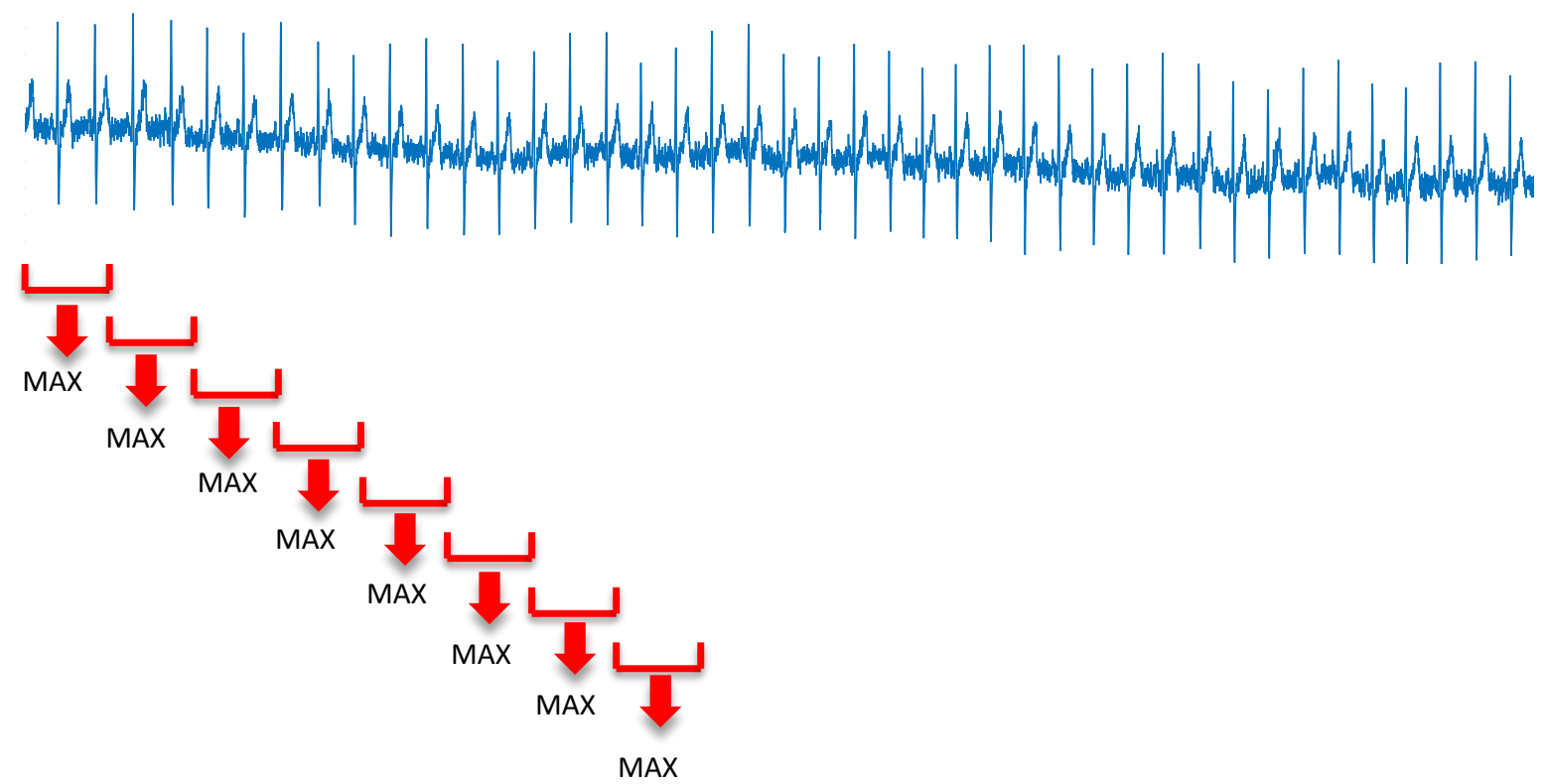

Figure 3. While loop for detecting ECG R wave peak every 1000 samples.

The cardiograph lab was one of eleven labs taught during ENGR 324L:Core Engineering Lab. This module was taught on week 5 . On the same day the cardiograph lab was taught, the first author administered a pre-assessment to all students. Students answered open-ended questions about what they were looking forward to and what concerns they had. Three weeks after the lab occurred, the first author administered post-assessments. Students addressed open-ended questions about what they most want to remember from the project, whether the project helped them envision themselves as an engineer, and what they learned about MATLAB. They also shared what they were most looking forward to, and concerns they had about Part IV of the cardiograph project. Students also repeated the 15 items on the StRIP Instrument [23].

\section{Findings}

On the pre-assessment, students were first asked what they are most looking forward to about the cardiograph project. Thirteen students (41\%) shared that they were excited to complete the project, as it had been two years since they started work on the cardiograph. Two of these students also noted that they wanted to see the different components of the project come together. Ten students (31\%) anticipated retrieving a clear signal, with six of these comments marveling at the ability to see their own heart's signal, as opposed to a stimulated one. Seven respondents (22\%) were eager to learn how to code, and one student wanted to improve their graphing abilities specifically.

Students were also asked if they had any concerns about the project. Nine students (28\%) were concerned about coding their projects correctly. Five students (16\%) were worried about the time commitment for the project (e.g., two students were worried about having to work on the project outside of class and one was concerned about balancing the project with his or her class workload). Only five students (16\%) were anxious that they lacked the general knowledge to be successful with the project. One of these students mentioned concern about his or her MATLAB skills in particular. 
After the first author conducted the pre-assessment, she and the main lab instructor helped groups with MATLAB steps. During this time, she observed that students were having difficulty with rudimentary functions, such as plotting in the time domain and plotting in the frequency domain. Students did not finish the lab during the allotted two hours, but later attended the main instructor's office hours for further assistance with coding peak detection with a while loop.

On the post-assessment, students were asked what they would like to remember from analyzing their own ECGs and to share "ah-ha" moments. Ten students (29\%) wanted to remember how to code and use different MATLAB functions. Nine students (26\%) wrote that they wanted to remember how to analyze signals and heartbeats. Seven students (21\%) would like to reprise their knowledge about reading different ECG waves. Five students (15\%) remarked that seeing ECGs graphed was an "ah-ha” moment. Two participants (6\%) wanted to remember the teamwork.

Twenty-six students (76\%) reported that this activity helped them envision themselves as future engineers, six said that it did not help them (18\%), and two did not respond. Of the 26 students who agreed that the project helped them see themselves as future engineers, seven (27\%) explained that it did so by teaching them to code and use MATLAB. Six (23\%) shared that analyzing "real world data" was particularly influential, while three others (12\%) noted that developing an understanding of signals allowed them to see themselves as future engineers. Another three respondents (12\%) remarked that the activity helped them engage in the type of problem-solving engineers practice. Two students (8\%) explained that working with medical devices helped them gain insight into what a future working with these devices would look like. Two other students (8\%) would like to work on similar analyses and projects in the future. One student (4\%) realized that he or she would like to focus on programming new inventions, and another learned about the extent to which engineers need to be knowledgeable about software.

Of the six students who did not think this activity helped them envision themselves as future engineers, three (50\%) explained that the project did not match their interests. One of these students would have appreciated a focus on environmental engineering. However, two of the three students found the coding useful, although in varying degrees.

Thirty students (88\%) believe that this activity helped them improve their MATLAB skills. When asked to explain how this activity helped them improve their MATLAB skills, fourteen students (47\%) wrote that they were able to practice, enhance, or reinforce pre-existing skills. Twelve students (35\%) learned new skills, techniques, or functions. Some of the new skills students reported learning include plotting features, filtering a signal, and creating scripts. Four students (13\%) shared that they appreciated having to troubleshoot and find their own resources to resolve issues.

Students were asked what they were most looking forward to about continuing the cardiograph project next semester, and 30 students submitted responses. Most participants were excited to complete the project and have a finished cardiograph (19 students, 63\%). Two of these students noted that they were looking forward to sharing this cardiograph accomplishment with 
future employers. Six students (20\%) remarked that they were excited to put together the different components of the cardiograph they worked on during the past semesters. Two students (7\%) were eager to complete college with a working cardiograph. Two others (7\%) were excited to learn more in general and about the cardiograph.

When asked if they had any concerns for the cardiograph project next semester, eleven out of 27 respondents (41\%) wrote that they had none. The remaining respondents had a range of concerns. Three students (11\%) were worried that the next semester would be online rather than in person, with one respondent explaining that most of the current semester was online and that made things difficult. Two (7\%) were concerned about the relevance of the project to their future goals. One of these respondents noted that they were not interested in biomedical engineering and its associated projects. Another two (7\%) students were uneasy about the amount of time that would be devoted to coding. One of these respondents wrote, "running into errors is innately frustrating." Two more students (7\%) were put off by the piecemeal process, with one explaining that it was hard to stay excited about the project when it is spread out across several semesters. One student (4\%) was nervous about continuing the project, writing, "it's intimidating to learn so much about something that used to be 'untouchable' for me.”

Students' responses to the StRIP Instrument are detailed in Table 1. The four StRIP subscales were considered at the beginning of semester 5 and at week 8 of semester 5 , after the cardiograph lab was completed. Overall, these findings demonstrated that students are engaged in the engineering curriculum. Student engagement was initially high, and did not significantly change after experiences with the cardiograph lab, as shown by student ratings on the Value, Positivity, and Participation subscales. However, student ratings on the Distraction subscale significantly decreased.

After speaking with the faculty members who used MATLAB in linear systems and circuits courses during semester 4, it was determined that this cardiograph assignment during semester 5 was the first time students coded in MATLAB without being first given foundational code.

\section{Discussion}

Based on observations and feedback, students demonstrated engagement during the cardiograph lab. Faculty at the moment questioned the engagement, since students were initially frustrated by their inexperience with MATLAB coding “from scratch.” The majority (88\%) believed that this activity helped them improve their MATLAB skills. Students participated actively, and tried their hardest to do a good job. They also felt the time used for the activity was beneficial, and saw value in the activity.

Post-assessment feedback points to ways to improve student engagement moving forward. In subsequent years, the slides introducing the cardiograph lab will provide real-world examples of how MATLAB is used in environmental engineering and computer engineering, as well as in biomedical engineering. The third author questioned the need for acquiring individual student ECG waveforms, when one person's ECG waveform could be given to the entire class to process. However, since students appreciate processing their own ECG waveform, rather than a simulation, student ECG recordings will continue in future years. 
Table 1. Means $(M)$ and standard deviations $(S D)$ for Junior responses to items from the Student Response to Instructional Practices (StRIP) Instrument by subscale and item pre- and post-activity.

\begin{tabular}{|c|c|c|c|c|c|}
\hline & \multicolumn{2}{|c|}{$\begin{array}{l}\text { Beginning of } \\
\text { Semester } \\
(2019, N=15)\end{array}$} & \multicolumn{2}{|c|}{$\begin{array}{c}\text { Post-activity } \\
\text { Week } 8(2019 \\
\& 2020, N=31)\end{array}$} & \multirow[t]{2}{*}{ Difference } \\
\hline & $M$ & $S D$ & $M$ & $S D$ & \\
\hline \multicolumn{6}{|l|}{ Value Subscale } \\
\hline $\begin{array}{l}\text { I felt the time used for the activity was } \\
\text { beneficial. }\end{array}$ & 4.07 & .70 & 4.13 & .85 & .06 \\
\hline I saw the value in the activity. & 4.13 & .64 & 4.19 & .87 & .06 \\
\hline $\begin{array}{l}\text { I felt the effort it took to do the activity } \\
\text { was worthwhile. }\end{array}$ & 3.93 & .70 & 3.87 & .89 & -.04 \\
\hline Average item response on Value Subscale & 4.04 & .68 & 4.06 & .87 & .02 \\
\hline \multicolumn{6}{|l|}{ Positivity Subscale } \\
\hline I felt positively towards the instructor. & 4.07 & .59 & 4.32 & .70 & .25 \\
\hline $\begin{array}{l}\text { I felt the instructor had my best } \\
\text { interests in mind. }\end{array}$ & 4.47 & .83 & 4.35 & .66 & -.12 \\
\hline I enjoyed the activity. & 3.93 & .70 & 3.81 & .79 & -.12 \\
\hline Average item response on Positivity Subscale & 4.16 & .71 & 4.13 & 0.72 & -.03 \\
\hline \multicolumn{6}{|l|}{ Participation Subscale } \\
\hline $\begin{array}{l}\text { I participated actively (or attempted } \\
\text { to). }\end{array}$ & 4.50 & .65 & 4.68 & .48 & .18 \\
\hline I tried my hardest to do a good job. & 4.47 & .52 & 4.61 & .56 & .14 \\
\hline $\begin{array}{l}\text { I pretended to participate in the } \\
\text { activity. (R) }\end{array}$ & 4.80 & .41 & 4.90 & .30 & .10 \\
\hline $\begin{array}{l}\text { I did not actually participate in the } \\
\text { activity. (R) }\end{array}$ & 4.53 & 1.25 & 4.71 & 1.01 & .18 \\
\hline I gave the activity minimal effort. (R) & 4.60 & .83 & 4.81 & .48 & .21 \\
\hline Average item response on Participation Subscale & 4.58 & .73 & 4.74 & .57 & 0.16 \\
\hline \multicolumn{6}{|l|}{ Distraction Subscale } \\
\hline $\begin{array}{l}\text { I distracted my peers during the } \\
\text { activity. }\end{array}$ & 1.60 & .63 & 1.35 & .55 & -.25 \\
\hline $\begin{array}{l}\text { I talked with classmates about other } \\
\text { topics besides the activity. }\end{array}$ & 2.07 & .96 & 1.65 & 61 & -.42 \\
\hline $\begin{array}{l}\text { I surfed the internet, checked social } \\
\text { media, or did something else instead of } \\
\text { doing the activity. }\end{array}$ & 1.20 & .41 & 1.00 & .00 & -.20 \\
\hline $\begin{array}{r}\text { Average item response on } \\
\text { Distraction Subscale }\end{array}$ & 1.62 & 0.67 & 1.33 & 0.39 & $-0.29 *$ \\
\hline
\end{tabular}

Response options for each item were: $1=$ almost never ( $<10 \%$ of the time); $2=$ seldom ( $\sim 30 \%$ of the time); $3=$ sometimes $(\sim 50 \%$ of the time); $4=$ often $(\sim 70 \%$ of the time); $5=$ very often $(>90 \%$ of the time $) .(\mathrm{R})=$ reverse item. $*$ = statistically significant difference $\mathrm{p}<0.001$ in paired sample t-tests

In this study, we saw evidence of quality teaching in STEM and strong interactions between faculty and students. Even though students found Part III of the cardiograph less enjoyable than Part II, they felt positively towards their instructors and felt the instructors had 
their best interests in mind. These feelings contributed to overall student engagement in Part III, their MATLAB coding, and may contribute to persistence in the program. In their classic ethnographic study of 460 science, mathematics, and engineering (SME) students from fifteen four-year institutions from 1990-1993, Seymour and Hewitt found that the third most commonly-cited factor (36.1\%) for switching out of SME was poor teaching by SME faculty. Poor teaching by SME faculty was also mentioned as a concern by $90.2 \%$ of all switchers and by $73.7 \%$ of non-switchers [24]. In their follow-up ethnographic study of 346 students from six four-year institutions, Seymour and Hunter observed that poor quality of STEM teaching is now the seventh most commonly-cited factor (48\%) for switching [25].

Having built three-fourths of their cardiographs through situated learning, $76 \%$ of students reported that the cardiograph lab helped them envision themselves as future engineers. MATLAB coding is a fundamental task that engineers use in industry, regardless of their specialization. Analyzing real-world data, including signals, is also a common industrial task. These knowledgeable skills enabled students to self-identify as engineers [18], as they more fully participated in their community [26]. This increased sense of belonging to the engineering community may also contribute to persistence in the program. In their follow-up ethnographic study, Seymour and Hunter observed that $52 \%$ of switchers were negatively affected by their difficulties in developing a sense of belonging to their STEM program [27]. It was encouraging that most students (63\%) were excited to complete the project and have a finished cardiograph.

"A limitation of this study is the lack of a control or comparison group that did not engage in the cardiograph project, or in other forms of active learning. We are unable to provide a control group at LUC, as our entire curriculum is built on active learning" [4]. A second limitation is that StRIP pre-assessment data was available for cohort 2021, but not for cohort 2022.

\section{Conclusion}

Through a four-semester cardiograph project, Loyola University Chicago is investigating the hypothesis that curricular contextual thread problem-based learning activities increase student engagement and student retention. The findings from this third project phase demonstrate that the cardiograph project continues to facilitate student engagement in the curriculum. Through a challenging MATLAB lab exercise for processing individual student ECG waveforms, students improved their MATLAB coding skills. This lab also helped students envision themselves as future engineers. This study will continue to investigate additional cohorts of students and the final part, Part IV, of this curricular thread.

\section{References}

[1] J. L. Morrison, The best school : West Point, 1833-1866. Kent, Ohio: Kent State University Press, 1998.

[2] B. L. Shoop and E. K. Ressler, "Developing the Critical Thinking, Creativity and Innovation of Undergraduate Engineering Students," International Journal of Engineering Education, vol. 27, pp. 1072-1080, 2011. 
[3] G. M. Novak, Just-in-time teaching : blending active learning with web technology. Upper Saddle River, NJ: Prentice Hall, 1999.

[4] G. Baura, L. Kallemeyn, N. Arroyo, V. C. F. Chen, and A. Beale, "Work in Progress: Building a Functional Cardiograph over Four Semesters," presented at the ASEE Annual Conference, Salt Lake City, UT, 2018.

[5] S. Freeman, S. L. Eddy, M. McDonough, M. K. Smith, N. Okoroafor, H. Jordt, et al., "Active learning increases student performance in science, engineering, and mathematics," Proceedings of the National Academy of Sciences of the United States of America, vol. 111, pp. 8410-8415, Jun 102014.

[6] R. R. Hake, "Interactive-engagement versus traditional methods: A six-thousand-student survey ofmechanics test data for introductory physics courses," American Journal of Physics, vol. 66, pp. 64-74, 1998.

[7] L. Springer, M. E. Stanne, and S. S. Donovan, "Effects of Small-Group Learning on Undergraduates in Science, Mathematics, Engineering, and Technology: A Meta-Analysis," Review of Educational Research, vol. 69, pp. 21-51, 1999.

[8] R. A. Streveler and M. Menekse, "Taking a Closer Look at Active Learning," Journal of Engineering Education, vol. 106, pp. 186-190, 2017.

[9] Z. E. Dadach, "Quantifying the Effects of an Active Learning Strategy on the Motivation of Students," International Journal of Engineering Education, vol. 29, pp. 904-913, 2013.

[10] M. Prince, "Does active learning work? A review of the research," Journal of Engineering Education, vol. 93, pp. 223-231, Jul 2004.

[11] J. Strobel and A. van Barneveld, "When is PBL More Effective? A Meta-synthesis of Metaanalyses Comparing PBL to Conventional Classrooms," Interdisciplinary Journal of ProblemBased Learning, vol. 3, pp. 44-58, 2009.

[12] R. M. Felder, G. N. Felder, and E. J. Dietz, "A Longitudinal Study of Engineering Student Performance and Retention. V. Comparisons with Traditionally-Taught Students," Journal of Engineering Education, vol. 87, pp. 469-480, 1998.

[13] M. J. Prince and R. M. Felder, "Inductive Teaching and Learning Methods: Definitions, Comparisons, and Research Bases," Journal of Engineering Education, vol. 95, pp. 123-138, 2006.

[14] S. E. Severiens and H. G. Schmidt, "Academic and social integration and study progress in problem based learning," Higher Education, vol. 58, p. 59, November 082008.

[15] S. M. Lord, M. J. Prince, C. R. Stefanou, J. D. Stolk, and J. C. Chen, "The Effect of Different Active Learning Environments on Student Outcomes Related to Lifelong Learning," International Journal of Engineering Education, vol. 28, pp. 606-620, 2012.

[16] A. Johri and B. M. Olds, "Situated Engineering Learning: Bridging Engineering Education Research and the Learning Sciences," Journal of Engineering Education, vol. 100, pp. 151-185, 2011.

[17] J. Lave and E. Wenger, Situated learning : legitimate peripheral participation. Cambridge England ; New York: Cambridge University Press, 1991.

[18] A. Johri, B. M. Olds, and K. O'Connor, "Situative Frameworks for Engineering Learning Research," in Cambridge Handbook of Engineering Education Research, A. Johri and B. M. Olds, Eds., ed New York: Cambridge University Press, 2014, pp. 47-66.

[19] G. Baura, V. C. F. Chen, and L. Kallemeyn, "Building a Functional Cardiograph Over Four Semesters: Part 2 - Programming a Microcontroller," presented at the ASEE Annual Conference, Tampa, FL, 2019.

[20] G. D. Baura, Medical device technologies : a systems based overview using engineering standards. Waltham, MA: Elsevier/Academic Press, 2012.

[21] G. D. Baura, Medical device technologies : a systems based overview using engineering standards, 2nd ed. Waltham, MA: Elsevier/Academic Press, 2020.

[22] R. Marra and B. Bogue, "A.W.E. (Assessing Women In Engineering) - A Model For Sustainable 
And Profitable Collaboration," in 2003 ASEE Annual Conference \& Exposition, Nashville, TN, 2003.

[23] M. DeMonbrun, C. J. Finelli, M. Prince, M. Borrego, P. Shekhar, C. Henderson, et al., "Creating an Instrument to Measure Student Response to Instructional Practices," Journal of Engineering Education, vol. 106, pp. 273-298, Apr 2017.

[24] E. Seymour and N. M. Hewitt, Talking about leaving: why undergraduates leave the sciences. Boulder, CO: Westview Press, 1997.

[25] A.-B. Hunter, "Why Undergraduates Leave STEM Majors: Changes Over the Last Two Decades," in Talking about Leaving Revisited: Persistence, Relocation, and Loss in Undergraduate STEM Education, E. Seymour and A.-B. Hunter, Eds., ed Cham, Switzerland: Springer, 2019, pp. 87-114.

[26] K. Tonso, "Engineering Identity," in Cambridge Handbook of Engineering Education Research A. Johri and B. Olds, Eds., ed Cambridge: Cambridge University Press, 2014, pp. 267-282.

[27] D. G. Holland, "The Struggle to Belong and Thrive," in Talking about Leaving Revisited: Persistence, Relocation, and Loss in Undergraduate STEM Education, E. Seymour and A.-B. Hunter, Eds., ed Cham, Switzerland: Springer, 2019, pp. 277-327. 